\title{
A fotografia como mediador cultural na construção do conhecimento histórico escolar ${ }^{*}$
}

\author{
The photograph as cultural mediator in the construction of \\ historical school knowledge
}

Natália Germano Gejão*

RESUMO

Este trabalho tem como proposta o estudo This work has as proposal the study on the sobre o potencial cognitivo da imagem que cognitive potential of the image that allows to permite inseri-la no conjunto de mediadores insert it in the group of cultural mediators parculturais participantes do processo de ticipants of the construction process of the acaconstrução do conhecimento histórico escolar. demic historical knowledge. The reflection leaA reflexão parte dos referenciais teóricos do ves of the theoretical references of the image conceito de imagem e da possível relação entre con-cept and of the possible relationship Imagem e História, onde estão envolvidas as between Image and History, where are envolnoções de cultura visual e História Visual ved concepts of visual culture and Visual Hispropostas por Ulpiano Meneses, para, então, tory proposed by Ulpiano Meneses, for, then, focar-se na relação entre fotografia e História e to focus in the relationship between photograna possibilidade de uso da imagem fotográfica, phy and History and in the possibility of photoentendida como uma construção histórica que graphic image use in the discipline teaching atua como vetor para a investigação da with taken as a historical construction that acts organização, funcionamento e transformação as vector for the investigation of the organizade uma sociedade, no ensino da disciplina. tion, functioning and transformation of a soDefende-se, ainda, a superação do status de ciety. And it defends the overcome of the illusilustração ao qual é, muitas vezes, limitada tration status to which is, a lot of times, limited dentro do processo de ensino e aprendizagem. inside of the teaching and learning process.

PALAVRAS-CHAVE: Ensino de História; visuali- KEYwORDS: Teaching of History; visuality; dade; História Visual; fotografia; mediador Visual History; photography; cultural mediacultural; conhecimento histórico escolar. tor; historical school knowledge.

Em meio a sociedades cada vez mais bombardeadas por imagens, torna-se necessário, no campo historiográfico, refletir sobre a presença destas em pesquisas e, principalmente, na prática do ensino de História. A reflexão recai sobre a forma como as imagens vêm sendo utilizadas no campo da História, buscando refutar a tradição que as tem como meras ilustrações a textos escritos.

\footnotetext{
Pesquisa orientada pela Profa. Dra. Ana Heloisa Molina, professora da Universidade Estadual de Londrina (UEL), e financiada pela Fundação Araucária.

* Mestranda em História Social da Universidade Estadual de Londrina (UEL) / Brasil.
} 
Neste sentido, este trabalho busca discorrer sobre os referenciais teóricos do conceito de imagem, a possível relação entre Imagem e História, e mais especificamente, entre fotografia e História, focando a atenção na possibilidade de uso da fotografia no ensino da disciplina, e em sua contribuição na construção do conhecimento histórico escolar.

Ao referir-se às imagens deve-se considerar a pluralidade que compõe a "iconosfera"1 atual. Dentre elas estão as imagens indiciais, que possuem uma referência material, e as imagens imateriais ou virtuais, criados pelo computador, presentes em um número cada vez maior.

Annateresa Fabris em seu artigo "Redefinindo o conceito de imagem" (1998) alerta para o risco dos trabalhos com imagens se aterem ao conceito de representação, pois este evoca a idéia de que sempre existe uma relação entre a imagem e a realidade exterior. A imagem virtual "é produto de uma abstração formal que sintetiza uma imagem ex nihilo e confere autonomia simbólica aos objetos conceituais que dela derivam” (1998: 7). As imagens produzidas por computadores não possuem um referencial material, elas são criadas e ganham significados ao serem consumidas.

Para a pesquisa histórica o foco recai sobre as imagens figurativas, pois, no figurativo encontra-se a condição humana básica de expressar seus sentimentos, emoções, idéias, através de figuras, cores e formas. (MOLINA, 2007). Ao trabalhar com imagens figurativas remetemo-nos ao abstrato, o que requer outras ferramentas cognitivas para a compreensão de suas mensagens tais como sentimentos, idéias e emoções.

Neste ponto, destaca-se a necessidade de os historiadores deslocarem a atenção das fontes visuais para a visualidade, que consiste numa importante dimensão da vida e dos processos sociais, sendo detentora de historicidade. Assim seria possível o reconhecimento do potencial cognitivo das imagens (MENESES, 2003).

Meneses afirma que foi apenas no século XVIII, através da História da Arte, que este potencial foi reconhecido. No contexto da Revolução Francesa, percebeu-se o uso de imagens como instrumento de luta política e revolucionária, sendo entendidas como monumentos históricos que permitem

1 O termo iconosfera é utilizado por Ulpiano B. Meneses em seu artigo "Fontes Visuais, Cultura Visual, História. Balanço provisório, propostas cautelares" (2003). Refere-se ao conjunto de imagens que, num dado contexto, está socialmente acessível. 
estabelecer uma relação visual com o passado. E, no final do século XIX, começo do século XX, a História da Arte "começou a encaminhar-se para a aceitação dos direitos de cidadania da fonte iconográfica, sobretudo mais tarde nos domínios da História Cultural" (Ibidem: 13).

O reconhecimento do potencial cognitivo da imagem permite sua aceitação como fonte de estudo. Meneses cita o exemplo de Baxandall que, sem pretender fazer uma História Social da Arte, demonstrou como os fatos sociais conduzem ao desenvolvimento de hábitos e mecanismos visuais que se convertem em elementos identificáveis no processo de produção e no consumo de imagens. (Ibidem: 14)

Portanto, além da preocupação com o processo de produção, circulação e recepção de imagens, mais significativo é entendê-las como elementos que participam das relações sociais. Neste sentido, o foco recai também sobre a "ação das imagens", os efeitos provocados, a produção e a sustentação de formas de sociabilidade, a legitimação de propostas de organização e atuação de poder. Assim se completaria o circuito social da imagem (produção, circulação, apropriação e ação).

Para Meneses, apesar do reconhecimento, a partir da década de 1960, da importância das fontes visuais e da ampliação da noção de documento, devido ao aparecimento de novos temas abordados pela historiografia, como a história da vida privada, das relações interpessoais, das mentalidades, que exigiam novas fontes de estudo, a História ainda está à margem das realizações nos demais campos das ciências humanas e sociais, no que se refere à questão da visualidade. Pesquisas que consideram de forma pertinente as imagens, limitam-se, geralmente, à História da Arte, ou àquelas onde há escassez documental, ou seja, quando as fontes escritas são de difícil acesso. O autor afirma que "os textos de história, geralmente, têm por objetivo iluminar as imagens com informações históricas externas a elas, e não produzir conhecimento histórico novo a partir dessas mesmas fontes visuais" (Ibidem: 18).

Apesar dos esforços de alguns pesquisadores como Ana Maria Mauad, Annateresa Fabris, Bóris Kossoy, entre outros, a História continua a ver a imagem como ilustração, ou seja, mera confirmação de conhecimento produzido por outras fontes, ou apenas como um elemento estético. Quando, de fato, 
A fotografia como mediador cultural na construção do conhecimento histórico escolar

deveria aproveitar das fontes visuais para delas extrair informações sobre o passado, pois, como afirma Peter Burke, as imagens podem ser tomadas como evidências ou testemunhos do passado, que permite reconstruí-lo "de forma mais vívida", a partir do conhecimento de elementos da cultura material deste passado, por exemplo. Para tanto, o historiador deve estar atento à fragilidade da imagem e fazer com que recaia sobre ela a critica da evidência visual (2004). ${ }^{2}$

Meneses defende o estudo da cultura visual de uma sociedade, de forma a abordar questões sobre as transformações que nela ocorrem. Para este campo de estudos dá o nome de História Visual 3 e acrescenta que as séries iconográficas usadas nas pesquisas não devem constituir-se em objetos de investigação em si, mas "vetores para investigação de aspectos relevantes na organização, funcionamento e transformação de uma sociedade”. (2003: 28) A História Visual consistiria não em uma história a partir de fontes visuais, mas de qualquer tipo de documento com o objetivo de analisar a dimensão visual da sociedade.

Para tanto, é necessário percorrer o ciclo completo da produção, circulação, consumo e ação das imagens, pois estas só possuem sentido através da interação social que mobiliza determinados atributos como o tempo, espaço, lugares, agentes, que dão existência social a ela, carregam-nas de sentidos e valores e assim fazem-nas atuar.

Ao refletir sobre a problemática da visualidade, como Meneses propõe, considerando a diversidade de imagens que compõe a "iconosfera", é posta a seguinte questão: quais as significações e repertórios interpretativos utilizados na leitura das imagens?

Primeiramente, é preciso ter em mente que ao observar uma imagem, uma pintura, por exemplo, não é possível explicá-la, mas sim falar sobre a observação que foi feita dela. (BAXANDALL apud MOLINA, 2007: 18) Cada indivíduo que tentar ler essa imagem estará carregando sua explicação de todo o seu repertório cultural, emocional e sígnico, o que permite leituras diferentes de um mesmo quadro, por exemplo.

As imagens passam por variadas leituras em diferentes contextos e épocas,

\footnotetext{
2 Ainda, o autor afirma que o testemunho das imagens, assim como o dos textos, suscita problemas de contexto, função, retórica, recordação, testemunho de segunda mão, entre outros.

3 O autor deixa claro que o termo História Visual não acompanha nenhuma proposta de estabelecimento de uma nova compartimentação da História.
} 
sobre elas se acumulam diferentes discursos realizados por observadores que "constroem sua descrição segundo as formas de contemplação, bagagem cultural ou as formas de apropriação da sociedade em que se insere." (SALGUEIRO apud MOLINA, 2007: 21) Portanto, para a interpretação da mensagem visual é também importante a familiarização com os códigos culturais do período de produção, assim como com os do período de consumo.

Os significados da imagem estão inseridos dentro de um sistema de representações condicionadas por convenções culturais. Para a leitura da imagem faz-se necessário um trabalho de decodificação da mensagem visual. Ana Heloisa Molina alerta para o fato de que "entre a imagem e o que se representa, existe uma série de mediações, que não restituem o real, mas reconstroem, voluntária ou involuntariamente, a apresentação deste real" (MOLINA, 2007: 22) Aqui está corrigido um equivoco muito comum nos trabalhos com imagem, pois muitos historiadores a identificam como o "reflexo" do real, correndo o risco de perder a historicidade da questão, quando na verdade, a ela consiste numa visão de mundo de alguém, onde estão presentes experiências de um individuo ou de uma coletividade, em um dado momento.

Toma-se o caso da fotografia para se pensar a construção e a significação da imagem. Por muito tempo a imagem fotográfica esteve restrita ao status de "espelho da realidade". Após sua invenção no século XIX, no contexto da Revolução Industrial, percebeu-se a possibilidade de se documentar através da câmera os costumes dos povos, habitações, mitos, religiões, fatos sociais e políticos, acreditando-se estar ali um retrato fiel da realidade. Afirmava-se que suas condições técnicas de produção, onde é a máquina que realiza a ação, permitiam o registro preciso do aparente. A fotografia, portanto, era tida como a expressão da verdade.

No entanto, sabe-se que no ato do registro fotográfico, o autor da imagem tem papel essencial. É ele quem escolhe um aspecto determinado, ou melhor, selecionado do real para compor a imagem. Impõe seu tratamento estético na organização visual dos detalhes, bem como a exploração dos recursos oferecidos pela tecnologia, da qual ele detém o conhecimento. Segundo Kossoy, "o registro visual documenta a própria atitude do fotógrafo diante da realidade, seu estado de espírito e sua ideologia acabam transparecendo em suas imagens" (KOSSOY, 2001: 43) . 
A cena congelada na fotografia é, portanto, um fragmento do real, uma escolha dentre várias possíveis, que obedece tanto a limitações técnicas, quanto a convenções culturais de produção e consumo. A imagem fotográfica em sua dimensão visual elege um elemento principal, o foco, e ignora toda a dimensão existente ao seu redor, aquilo que a fotografia não mostra e que tem valor na interpretação de seu significado.

Reinaldo Nishikawa ao abordar o caráter seletivo da fotografia afirma que, apesar de sua riqueza de detalhes, a imagem fotográfica é pobre quanto a um plano geral.

É como um homem num quarto escuro, com apenas uma vela acesa em suas mãos. Sua realidade consiste apenas naquele pequeno lume produzido pela vela. Aquele naco de luz, aquela pequena claridade, representa sua realidade observável, tanto quanto possível. Não é toda a realidade, sem, contudo, deixar de ser parte do real (NISHIKAWA, 2005:1803).

Neste sentido, a imagem fotográfica transpõe a idéia de real, se aproxima da lógica do semelhante ou substituto do real. (GRANET-ABISSET, 2002) No entanto, é também um vestígio de uma materialidade, pois só pode existir a partir de uma modelo posto diante da lente da câmera. Por atestar a existência de uma realidade, Ana Maria Mauad, pautada em uma abordagem históricosemiótica da fotografia, afirma ter esta a característica de um índice, ou seja, um indício, "resíduo da realidade sensível impressa na imagem fotográfica." (1996: 79).

Outros são os elementos relacionados à fotografia que devem ser analisados em trabalhos historiográficos que as tomem como fontes de estudo. 4 As imagens devem ser consideradas como produtos culturais compostos pelo o autor, como já mencionado, o texto visual e o leitor. Assim sendo, possui um local de produção e um produtor detentor de saberes específicos. O leitor fará a recepção da imagem de acordo com o contexto histórico em que vive. E o significado da mensagem fotográfica será aceito como válido socialmente devido a um trabalho de investimento de sentido, pois, trata-se de uma construção

\footnotetext{
4 Existem dois caminhos para pensar a relação entre fotografia e História: a História da Fotografia, que diz respeito ao estudo desse meio de comunicação e expressão em seu processo histórico, por exemplo a evolução das técnicas fotográficas ou os diferentes usos da fotografia numa dimensão social; História através da fotografia, onde esta passa a ser um instrumento de apoio à pesquisa, como um meio de conhecimento de uma cena passada, que permita descobertas sobre aspectos da visualidade de uma sociedade. Este trabalho se propõe a pensar o segundo caminho.
} 
histórica na medida em que é elaborada por um indivíduo inserido num conjunto de relações sociais, econômicas, culturais, políticas, e, até mesmo, estéticas.

A grande questão que se percebe quando se trabalha com este tipo de fonte é definir o que é a realidade fotográfica. Sendo interpretação, seleção, fragmento ou verdade, como muitas vezes é tomada, o importante é fazer com que recaia sobre ela a crítica histórica, semelhante ao que acontece com o documento escrito. Questões básicas devem ser feitas às fotografias/objeto: quem as produziu, quando, onde, qual a intenção do produtor, onde está localizada, por quais mãos já passaram, a quais usos já foram submetidas, entre outras.

Mauad. ao refletir sobre leituras e interpretações de fotografias como fontes históricas, defende que elas devem ser compreendidas como uma mensagem que se organiza a partir da expressão e o conteúdo. No segmento da expressão a análise recai sobre aspectos técnicos e estéticos da produção do registro fotográfico, tais como enquadramento, iluminação, definição, cor, entre outros. Já no segmento do conteúdo observa-se os elementos constituintes da cena congelada, tais como as pessoas, objetos, lugares, entre outros. (1996: 89)

Quanto à idéia de fotografia como representação Carlo Ginzburg em seu livro Olhos de Madeira: nove reflexões sobre a distância aborda a ambigüidade do termo:

\footnotetext{
Por um lado, a "representação" faz as vezes da realidade representada e, portanto, evoca a ausência; por outro, torna visível a realidade representada e, portanto, sugere a presença. Mas a contraposição poderia ser facilmente invertida: no primeiro caso, a representação é presente, ainda que como sucedâneo; no segundo, ela acaba remetendo, por contraste, à realidade ausente que pretendia representar (GINZBURG, 2001: 85).
}

A fotografia como representação insere-se neste quadro de ambigüidade, pois se é apresentada como realidade, ela não existe, portanto, "evoca a ausência", mas, por outro lado, é ela que apresenta o real, evoca seu sentido e sua permanência, "sugere presença", fazendo com que o real passe a existir para as pessoas que buscam analisar a imagem representada na fotografia.

O historiador, ao lançar mão desta importante fonte histórica em seu oficio, busca reconstruir aquele fragmento do real mediante um discurso e demonstrar que este faz parte da realidade, uma realidade muito mais ampla do que aparece na imagem, composta por elementos tão importantes quanto aqueles imortalizados pela fotografia. Ou seja, seu trabalho consiste numa 
tentativa de construir uma imagem desse real. Para tanto, é necessário dialogar com informações apresentadas por outras fontes, sejam imagéticas, orais ou escritas. Sem, no entanto, desperdiçar o potencial cognitivo da imagem fotográfica, relegando a ela o simples papel de ilustração, ou confirmação de conhecimentos produzidos por estas outras fontes.

Como fonte histórica, a fotografia deve compor séries, ou corpus de análise, no sentido de possibilitar a reflexão sobre semelhanças e diferenças próprias ao conjunto de imagens selecionadas, e esta seleção pode ser organizada por critérios diversos, tais como um tema específico (cenas familiares, eventos sociais, políticos, crianças, trabalho, entre outros), ou agências de produção (família, Estado, imprensa). (MAUAD, 1996).

$\mathrm{O}$ historiador ao tomar contato com essas imagens articula o sentido da interpretação, diferente daqueles dados pelos contemporâneos dela, ou por outros possíveis leitores. Como lembra Mauad, "as imagens não falam por si só, é necessário que perguntas sejam feitas.” (Ibidem: 91). E estas perguntas partem de questões do presente.

Os trabalhos com fotografias no ensino de História devem seguir estes mesmos critérios de análises para que as imagens ultrapassem o status de ilustração. Os professores, muitas vezes, ao se esforçarem para organizar atividades com imagens pretendem assim tornar suas aulas mais "atrativas", "ilustrativas", e então contribuir para que os alunos entendam melhor o conteúdo. Esta percepção sobre o trabalho com imagens em sala de aula também está presente no imaginário dos alunos, como pode-se perceber em pesquisa feita por Molina com alunos da oitava série do ensino fundamental, onde estes responderam a um questionário com perguntas sobre a observação de imagens, a utilidade do trabalho com imagens em sala de aula e a relação do professor de história ao explorar algum tipo de imagem em suas aulas. As respostas giraram em torno de termos como "entender melhor o conteúdo", "retratar alguns conhecimentos", "para mostrar integralmente um assunto", "para aprendermos de um jeito mais legal", entre outros ligados ao fator motivação (MOLINA, 2007).

Percebe-se que a noção de imagem como documento histórico ainda não alcançou o espaço da sala de aula. Molina afirma que os professores as utilizam como transmissores e não como mediadores de conhecimento, e defende que: 
(...) as imagens usadas em sala de aula não devem sê-lo gratuitamente, mas é necessário conhecer seus componentes semânticos para adequá-los aos objetivos propostos. Assim, o desafio e o limite imposto ao professor de história serão de redimensionar e explorar as competências específicas da imagem, não somente para motivar e envolver, mas re-elaborar, recodificar, ordenar e organizar conceitos, transformando uma relação sócio-afetiva com a imagem em uma situação de cognição (MOLINA, 2007: 25).

Toma-se mais uma vez o exemplo da fotografia, que superada a sua concepção de "expressão da verdade”, "reflexo da realidade”, pode atuar como importante instrumento pedagógico nas aulas de História. Para tanto, deve funcionar como um mediador cultural, ou seja, atuar na interação entre conhecimentos prévios e novos conhecimentos. Como em qualquer leitura de imagens, por serem condicionadas pela bagagem cultural do leitor e pelas formas de apropriação da sociedade em que se inserem, em sala de aula também serão construídos diferentes discursos sobre uma fotografia, já que se tem diferentes sujeitos. Daí a importância de se investigar os conhecimentos prévios dos alunos, tanto sobre o suporte imagético, quanto sobre o conteúdo da aula.

Nesse sentido, Lana Mara Siman afirma que a produção do conhecimento não ocorre diretamente entre sujeito e objeto, passa pela ação mediadora de professores, linguagens, signos, entre outros:

\begin{abstract}
Para que o ensino de História, todavia, seja levado a bom termo, (...), torna-se necessário que o professor inclua, como parte constitutiva do processo ensino/aprendizagem, a presença de outros mediadores culturais, como os objetos da cultura material, visual ou simbólica, que ancorados nos procedimentos de produção do conhecimento histórico possibilitarão a construção do conhecimento pelos alunos, tornando possível "imaginar", reconstruir o não-vivido, diretamente, por meio de variadas fontes documentais (2004: 88).
\end{abstract}

A fotografia, por ser uma linguagem imagética, atua como um mediador para a percepção do mundo e para o processo de construção do conhecimento sobre este mundo.

Portanto, se realizado um trabalho pedagógico planejado com fotografias, assim como outros suportes imagéticos, em sala de aula, que se assemelhe com o trabalho do historiador, que a tome como vetor para a investigação sobre a organização, funcionamento e transformações de uma sociedade e que leve em consideração os elementos constitutivos da imagem, seus dados técnicos, estéticos, seu contexto histórico de produção e consumo, sua participação nas relações sociais, que provocam efeitos, sustentam formas de sociabilidades e documentam as transformações na dimensão visual de uma sociedade, a 
fotografia pode confirmar seu status de fonte histórica e ferramenta pedagógica para a composição do conhecimento histórico escolar, pois, a escola também é lugar de produção de conhecimento em todas as áreas. 5

O professor possui em suas mãos um valioso material didático/pedagógico, que pode, muito além de tornar suas aulas mais atrativas, facilitar seu trabalho de mediação no processo de construção de conhecimento histórico pelos alunos. Para tanto, buscar conhecimentos específicos sobre o trabalho com as imagens e reservar tempo para o planejamento de atividades, pode auxiliá-lo a criar as oportunidades de os alunos entrarem em contato com o universo das imagens dentro da sala de aula, sem fazer da falta de recursos tecnológicos um empecilho para este trabalho.

Neste sentido, o ensino de História abre-se a multiplicidade de fontes e linguagens de produção do saber histórico, e possibilita a inclusão dos significados que os próprios sujeitos inseridos no processo de ensino/aprendizagem constroem a respeito do mundo em que vivem.

O objetivo central desse trabalho foi refletir sobre o potencial cognitivo das imagens, em geral, assim como sobre a dimensão histórica das fotográficas, em particular, e suas possibilidades de uso na composição do conhecimento sobre o passado. A atenção a esses aspectos permanece, portanto, como um desafio a ser enfrentado no campo da pesquisa e da prática do ensino de história.

\section{Bibliografia}

ABUD, Kátia Maria. Conhecimento Histórico e Ensino de História: a produção do conhecimento histórico escolar. In: SCHMIDT, Maria Auxiliadora e CAINELLI, Marlene (orgs.) III Encontro Perspectivas do Ensino de História. Curitiba: Aos Quatro Ventos, 1995.

BITTENCOURT, Circe. Livros didáticos entre textos e imagens. IN: (org). O saber histórico em sala de aula. São Paulo: Contexto, 1997.

BORGES, Maria Eliza Linhares. História \& Fotografia. $2^{\text {a }}$ ed. Belo Horizonte: Autêntica, 2005.

BURKE, Peter. Testemunha ocular: história e imagem. Bauru: EDUSC, 2004. CARDOSO, Ciro F.; MAUAD, Ana Maria. História e Imagem: os exemplos da

5 Esta questão vem sendo debatida desde a década de 1970, quando negou-se a fragmentação entre o saber, produto da academia, e o fazer, prática do professor da educação básica que reproduz o conhecimento formulado na academia. Ver Kátia Maria Abud (1995). Assim, entende-se que a escola possui um saber próprio, um saber escolar, produto das relações pessoais, sociais e pedagógicas existentes em seu espaço e cotidiano. 
fotografia e cinema. IN: CARDOSO, Ciro F.; VAINFAS, Ronaldo (orgs.). Domínios da História: ensaios sobre teoria e metodologia. Rio de Janeiro: Elsevier, 1997.

FABRIS, Annateresa. Fotografia: usos e funções no século XIX. $2^{\mathrm{a}}$ ed. São Paulo: Editora da USP, 1998.

- Redefinindo o conceito de imagem. IN. Revista Brasileira de História. São Paulo: ANPUH, v.18, n. 35, 1998.

FELIZZARDO, Adair e SAMIAN, Etienne. A fotografia como objeto e recurso da memória. IN: Discursos Fotográficos. v. 3, n. 3, 2007.

GRANET-ABISSET, Anne Marie. O Historiador e a Fotografia. Trad. Yara Aun Khoury. IN: Projeto História. São Paulo, n. 24, 2002.

KOSSOY, Boris. A fotografia como fonte histórica: introdução à pesquisa e interpretação das imagens do passado. São Paulo: Museu da Indústria, Comércio e Tecnologia de São Paulo, 1980.

. Fotografia \& História. $2^{\text {a }}$ ed. São Paulo: Ateliê Editorial, 2001.

1999.

. Realidades e ficções da trama fotográfica. Cotia: Ateliê Editorial,

MAUAD, Ana Maria. Através da Imagem: Fotografia e História - Interfaces. IN: Tempo. Rio de Janeiro, vol. 1, n. 2, 1996, pp. 73-98.

MENESES, Ulpiano B. Fontes Visuais, Cultura Visual, História. Balanço provisório, propostas cautelares. IN: Revista Brasileira de História, vol. 23, n. 45, 2003

MOLINA, Ana Heloisa. Ensino de História e Imagens: possibilidades de pesquisa. IN: Domínios da Imagem. Londrina, ano 1, n. 1, jul.-dez. 2007.

NISHIKAWA, Reinaldo. Retratos em preto e branco: uma discussão analítica sobre fontes fotográficas para o historiador. IN: Fragmentos de Cultura. Goiânia, v. 15, n. 12, pp. 1.797-1.810, dez, 2005.

SILVA, Marcos A. A construção do saber histórico: historiadores e imagens. IN: Revista de História. São Paulo, n.125-126, ago-dez/91 a jan-jul/92, pp. 117-134.

SIMAN, Lana Mara. O papel dos mediadores culturais e da ação mediadora do professor no processo de construção do conhecimento histórico pelos alunos. IN: ZARTH, Paulo A.; et al. (orgs.) Ensino de História e Educação. Ijuí: Ed. UNIJUÍ, 2004.

. Pintando o descobrimento: o ensino de História e o imaginário de adolescentes. In. SIMAN, Lana Mara e FONSECA, Thaís Nívia (orgs.). Inaugurando a História e construindo a nação. Discursos e imagens no ensino de História. Belo Horizonte: Autêntica, 2001.

Colaboração recebida em 29/03/2009 e aprovada em 21/06/2009. 